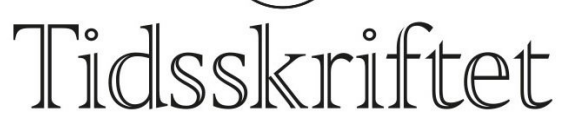

DEN NORSKE LEGEFORENING

\title{
Scandiatransplant 50 år - et vellykket nordisk samarbeid om organtransplantasjon
}

ESSAY

\section{ARNT JAKOBSEN}

Arnt Jakobsen er dr.med. og tidligere overlege ved Transplantasjonskirurgisk seksjon og sjeflege ved Rikshospitalet. Han var styreleder for Foreningen Scandiatransplant 2004-2010.

Forfatteren har fylt ut ICMJE-skjemaet og oppgir ingen interessekonflikter.

\section{TORBJ ØRN LEIVESTAD}

Torbjørn Leivestad er dr.med. og tidligere overlege og seksjonsoverlege ved Immunologisk institutt, Rikshospitalet. Han opprettet og drev Norsk Nyreregister og ledet en rekke faggrupper i Foreningen Scandiatransplant.

Forfatteren har fylt ut ICMJE-skjemaet og oppgir ingen interessekonflikter.

\section{PER PFEFFER}

Per Pfeffer er dr.med. og tidligere seksjonsoverlege ved Transplantasjonskirurgisk seksjon, Rikshospitalet. Han er tidligere styremedlem i Foreningen Scandiatransplant og president i Scandinavian Transplantation Society.

Forfatteren har fylt ut ICMJE-skjemaet og oppgir ingen interessekonflikter.

\section{ERIK THORSBY}

E-post: erik.thorsby@medisin.uio.no

Erik Thorsby er dr.med. og professor emeritus ved Avdeling for immunologi, Universitetet i Oslo. Han var tidligere sjef for Vevstypelaboratoriet og Institutt for transplantasjonsimmunologi, og senere avdelingssjef for Immunologisk institutt, Rikshospitalet og Universitetet i Oslo. Han etablerte fagområdet HLA og transplantasjonsimmunologi i Norge og var en av initiativtagerne til Scandiatransplant i 1968.

Forfatteren har fylt ut ICMJE-skjemaet og oppgir ingen interessekonflikter.

Scandiatransplant, den nordiske utvekslings- og samarbeidsorganisasjonen for organtransplantasjoner, fyller 50 år i år. Blant de over 2 ooo organtransplantasjonene som utføres årlig i medlemslandene, kommer mange av organene fra en nylig avdød donor i et naboland. Scandiatransplant har medvirket til at nordisk transplantasjonsmedisin er blant de aller beste internasjonalt.

Det største problemet ved alle organtransplantasjoner der giver og mottaker ikke er arvemessig identiske, er avstøtningsreaksjoner. Å hemme eller helst forhindre slike reaksjoner er helt sentralt for et vellykket resultat. Etter initiativ fra kirurgen Lars Erik Gelin (1920-80) ved Sahlgrenska sjukhuset i Göteborg ble det fra 1966 avholdt noen uformelle møter mellom leger som arbeidet med nyretransplantasjoner ved Sahlgrenska sjukhuset og 
Århus Kommunehospital, for å diskutere dette og andre felles problemer. Samtidig hadde man da fått de første holdepunktene for at uforlikelighet mellom giver og mottaker for HLA-vevstyper (HLA = humant leukocyttantigen) var en viktig årsak til avstøtningsreaksjoner (ramme 1).

\section{Ramme 1}

HLA-molekylene, eller HLA-vevstypene, sitter på overflaten av alle våre kjerneholdige celler. De finnes i svært mange ulike varianter, og ubeslektede individer har derfor oftest forskjellige HLA-vevstyper. Dersom giver og mottaker av et transplantat har forskjellige HLA-vevstyper, vil det ofte resultere i sterke avstøtningsreaksjoner, rettet mot de fremmede HLA-vevstypene hos giveren. Derfor ønsker man å finne frem til en giver som har mest mulig like HLA-vevstyper som mottakeren. Dette var særlig viktig før man fikk nye og mer effektive immunsupprimerende midler. Fortsatt er dette viktig for pasienter som har dannet antistoffer mot fremmede HLA-vevstyper, f.eks. på grunn av tidligere transplantater som er blitt avstøtt. I slike tilfeller må man finne et organ fra en giver som pasientens HLAantistoffer ikke reagerer med, for å unngå en meget rask (hyperakutt) avstøtning.

Det er ofte vanskelig å finne frem til en mottaker som har tilnærmet de samme HLAvevstypene som en ubeslektet, nylig avdød giver. Det må også være ABO-

blodtypeforlikelighet mellom giver og mottaker. Våren 1968 oppsøkte derfor den danske immunologen Flemming Kissmeyer-Nielsen (figur 1) og den unge norske HLA-forskeren Erik Thorsby daværende helsedirektør i Norge, Karl Evang (figur 2). De foreslo at det ble etablert et nordisk samarbeid om nyretransplantasjoner, hvor alle pasienter i Norden som ventet på en ny nyre fra en ubeslektet, nylig avdød giver, ble ABO-blodtypet og HLAvevstypet, og registrert i et felles nordisk register. Ved å ha mange mottakere å velge mellom ville det bli lettere å finne frem til HLA-forlikelige mottakere av nyrer fra en nylig avdød giver. Det årlige møtet mellom de nordiske helsedirektører skulle avholdes i Oslo samme år. Evang var som kjent en meget innflytelsesrik helsedirektør. Kissmeyer-Nielsen og Thorsby antok derfor at om de fikk overbevist ham om betydningen av et nordisk samarbeid, var mye vunnet. 


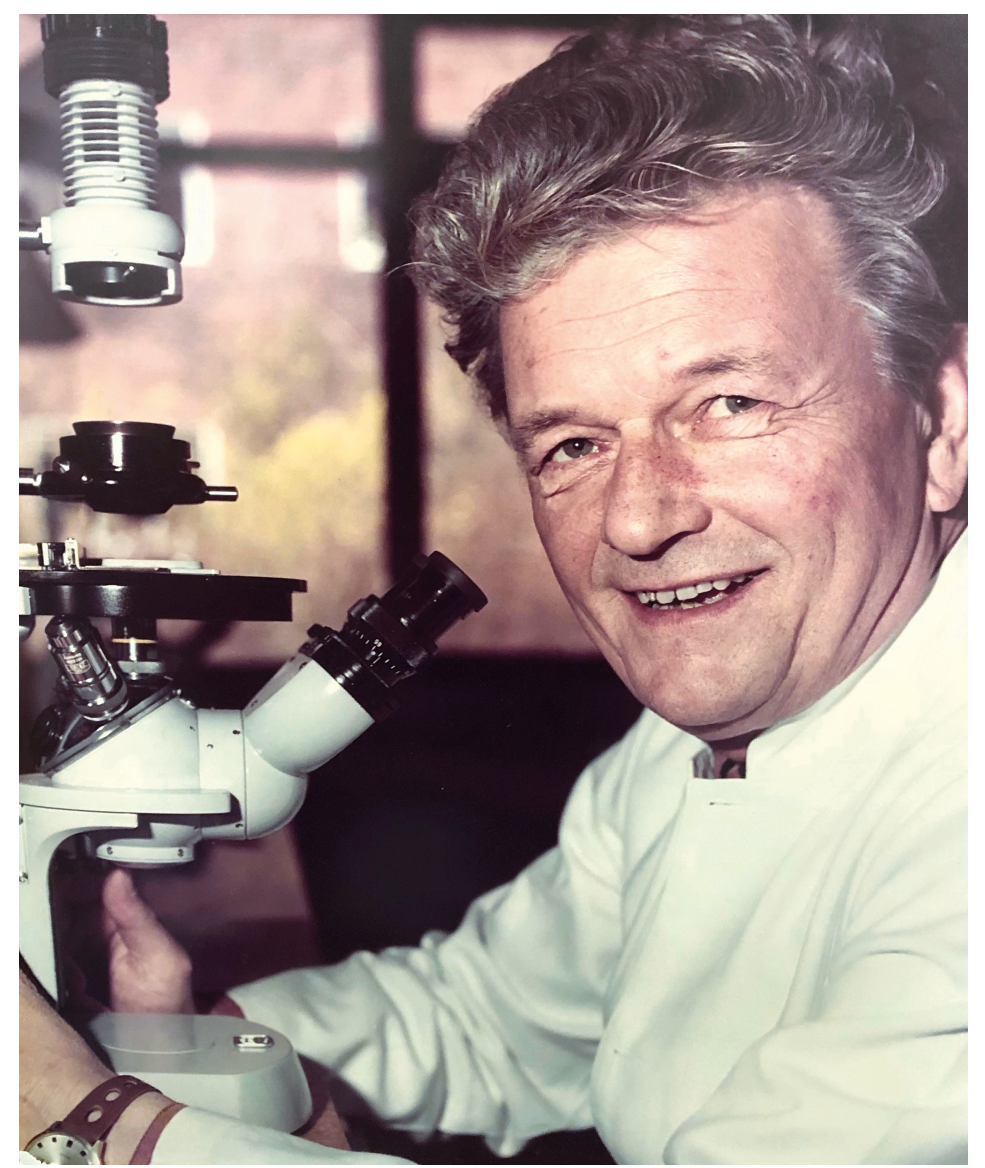

Figur 1 Flemming Kissmeyer-Nilsen (1921-91). Foto: Avdelingen Blodbank og Immunologi ved Aarhus Universitetshospital.

Evang lot seg overbevise. På det etterfølgende nordiske helsedirektørmøtet ble derfor Nordisk ekspertkomite for nyretransplantasjoner opprettet, hvor hvert nordisk land ble bedt om å oppnevne tre medlemmer hver. (Se ramme 2 for de første medlemmene.) De var alle pionerer innen utviklingen av nordisk transplantasjonsmedisin. De norske medlemmene var Leif Efskind (1904-87), professor i kirurgi ved Rikshospitalet, Ole Jacob Malm (1910-2005), professor i patofysiologi ved Ullevål sykehus, og Erik Thorsby, assistentlege samme sted. Efskind hadde utført den første nyretransplantasjonen i Norge og i Norden allerede i 1956 (1). Malm var sentral i den første nyretransplantasjonen ved Ullevål sykehus i 1963, en transplantasjon som var meget vellykket (1). Fra 1971 ble det også oppnevnt et medlem fra Island. Nordisk råd påtok seg å dekke komiteens utgifter.

\section{Ramme 2 De første medlemmene av Nordisk ekspertkomite for nyretransplantasjoner.}

\section{NORGE}

Leif Efskind, Rikshospitalet

Audun Flatmark, Rikshospitalet (sekretær)

Ole Jacob Malm, Ullevål sykehus

Erik Thorsby, Ullevål sykehus

\section{SVERIGE}

Curt Franksson, Karolinska Institutet, Stockholm Lars Erik Gelin, Sahlgrenska sjukhuset, Göteborg Bertil Hood, Sahlgrenska sjukhuset, Göteborg

\section{DANMARK}

Ole Fjeldborg, Århus Kommunehospital 
Jørn Hess Thaysen, Rigshospitalet, København

Flemming Kissmeyer-Nielsen, Århus Kommunehospital

\section{FINLAND}

Børje Kuhlback, Helsingfors Universitets Centralsjukhus Bjørn Lindstrøm, Helsingfors Universitets Centralsjukhus Martti Turunen, Helsingfors Universitets Centralsjukhus

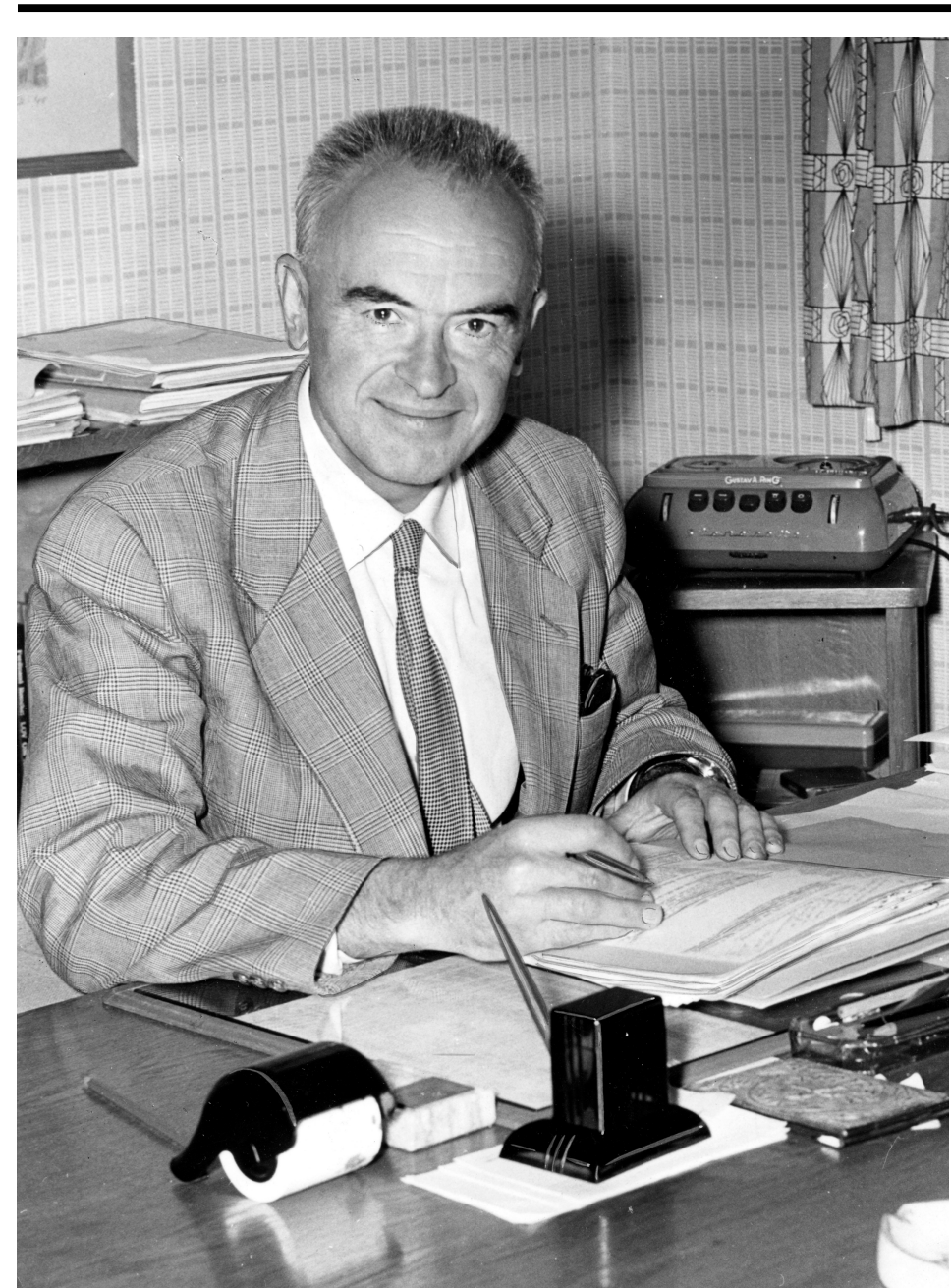

Figur 2 Karl Evang (1902-81). Foto: NTB Scanpix

Det første konstituerende møtet i komiteen ble holdt i Göteborg i februar 1969. Ved neste møte i juni samme år ble Audun Flatmark (1926-2004), nyansatt transplantasjonskirurg ved Rikshospitalet, oppnevnt som komiteens sekretær. Etter hvert ble han også fullt medlem av komiteen. Flatmark var den som bygget opp den moderne transplantasjonsmedisinen $\mathrm{i}$ Norge (1).

Ved møtet i juni 1969 ble også Scandiatransplant formelt etablert. (Siden Finland og senere også Island var medlemmer, ble det diskutert om navnet heller burde vært

Nordictransplant. Man valgte likevel Scandiatransplant.) Det ble opprettet et register ved Vevstypelaboratoriet ved Kommunehospitalet i Århus, hvor Flemming Kissmeyer-Nielsen var sjef. Pasienter i Norden som ventet på en ny nyre fra en nylig avdød giver, ble registrert med ABO-blodtype og HLA-vevstyper. Alle vevstypelaboratoriene i Norden hadde tilgang til dette registeret via fjernskriver. Når en nylig avdød giver ble tilgjengelig, ble det straks foretatt blod- og vevstyping, og det ble tatt kontakt med registeret i Århus for å finne frem til pasienter med optimal HLA-forlikelighet (figur 3). Om pasienten fantes i et annet nordisk senter, ble nyren fløyet dit. 


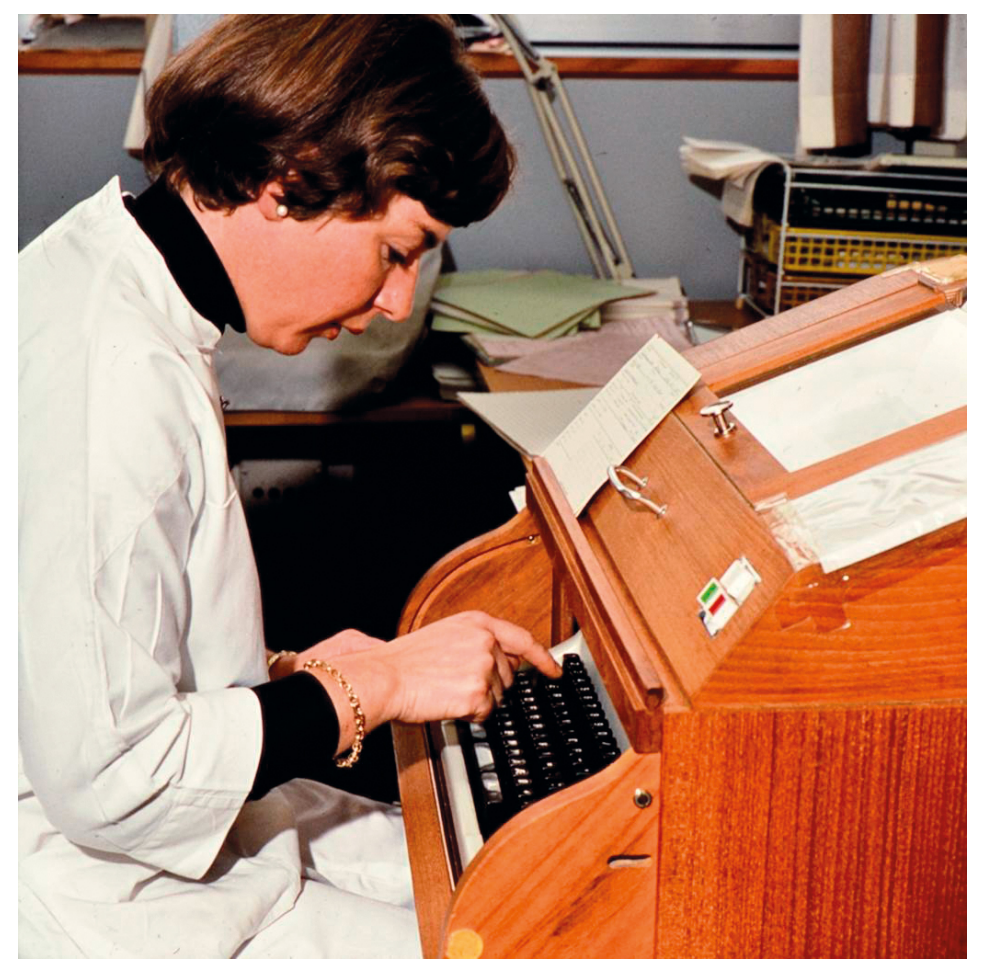

Figur 3 Sjefbioingeniør Anne Bratlie ved Vevstypelaboratoriet ved Rikshospitalet søker via fjernskriver i Scandiatransplantregisteret $i$ Aarhus etter HLA-forlikelige mottakere til nyrene fra en nylig avdød giver. Bildet er tatt omkring 1975. Foto: Erik Thorsby

Den nordiske ekspertkomiteen fungerte som en styringsgruppe for Scandiatransplant. Men komiteen tok også tidlig opp en rekke andre saker av stor betydning for utvikling av transplantasjonsmedisinen i Norden. Det viktigste de første årene var å legge forholdene til rette for at alle som hadde behov for nyretransplantasjon, kunne tilbys det. Lovgivningen vedrørende donasjon av organer fra nylig avdøde var en annen viktig sak. Flere innstillinger om disse og andre spørsmål ble oversendt de nordiske lands helsedirektører. Komiteen ble på denne måten et meget viktig samarbeidsorgan for transplantasjonsvirksomheten i Norden. Komiteen initierte og finansierte også en rekke nordiske forskningsprosjekter.

\section{Foreningen Scandiatransplant overtar}

Driften av Scandiatransplant, dvs. registeret i Århus, var ressurskrevende og trengte stadig fornyelser. Det ble forgjeves søkt om midler fra ulike kilder, inkludert myndighetene i de nordiske land. Redningen ble en donasjon på 3,2 millioner DKK fra det danske «Toyotas fond for samfundsmæssige og velgørende formaal» i 1992. Nordisk råd ønsket etter hvert at de enkelte nordiske land selv skulle overta finansieringen både av ekspertkomiteen og driften av Scandiatransplant. Dessuten hadde man så vidt begynt utveksling også av andre organer som hjerte, lever og lunge. Ekspertkomiteen laget derfor et forslag om å opprette Scandiatransplant som et fast samarbeidsorgan for all transplantasjonsvirksomhet i Norden, til erstatning for ekspertkomiteen.

Det «nye» Scandiatransplant, døpt Foreningen Scandiatransplant, ble opprettet i 1992. Samtidig ble ekspertkomiteen avviklet. Medlemmene av Scandiatransplant er nå de nordiske transplantasjonssykehusene. Organisasjonen er derfor helt styrt av fagpersoner. Fra 2017 ble også Estland medlem. Omkostningene dekkes av de involverte sykehusene, basert på antall organtransplantasjoner foregående år. I tillegg til å tilrettelegge for utveksling av ulike organer fra nylig avdøde for transplantasjon i Norden, driver organisasjonen også mye annen virksomhet på transplantasjonsfeltet $(3,4)$. Det inkluderer omfattende oppfølging for å kvalitetssikre resultatene, ulike faggrupper, felles krav til infeksjonstesting av givere og mottakere, og et nettverk av faglig samarbeid for å styrke forskning og utviklingsarbeid på området. 


\section{Utveksling av nyrer fra nylig avdøde}

Den første utvekslingen av en nyre fra en nylig avdød giver til en pasient i et annet nordisk land fant sted i mars 1969, da en nyre ble fløyet fra Göteborg til en pasient i Århus. En pasient i Norge fikk første gang en nyre fra Danmark juli 1969.

Primært prøvde man å finne mottakere som hadde de samme eller nesten de samme HLAvevstypene som giveren. Om en slik mottaker befant seg i et annet nordisk transplantasjonssenter, var det et krav at nyren måtte tilbys dette senteret. I 1971 ble hele $73 \%$ av nyrene fra nylig avdøde givere transplantert ved et annet senter enn donorsenteret (figur 4). Men helt problemfritt var dette ikke. Noen sentre, som det norske, utførte mange nyretransplantasjoner med levende giver (ca. $40 \%$ ), og fikk av den grunn en noe kortere venteliste enn andre sentre. Dessuten var tilgangen på avdøde givere klart større i noen land enn i andre. Dette førte til at noen sentre fikk langt lengre ventelister enn andre og derved langt flere organer tilsendt enn de selv tilbød. Man utviklet derfor i løpet av 1980-årene et slags «tilbakebetalingssystem». Om et senter hadde sendt ut flere nyrer enn det hadde mottatt, skulle dette utlignes i løpet av et halvt år med nyrer av sammenlignbar ABOblodtype og organkvalitet.

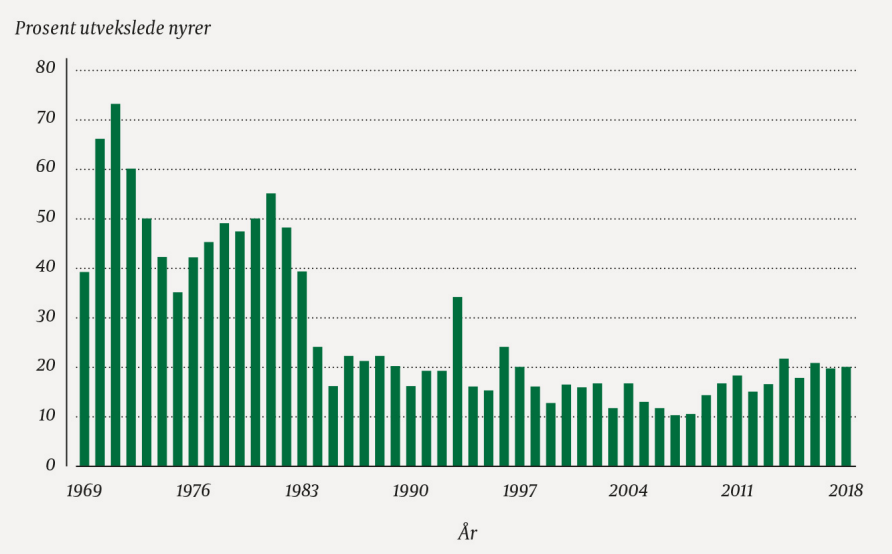

Figur 4 Andel nyretransplantasjoner med nyre fra nylig avdød giver sendt fra ett nordisk senter til et annet siden starten av Scandiatransplant $i 1969$ (4).

Betydningen av god HLA-forlikelighet mellom giver og mottaker var klar i 1970- og begynnelsen av 1980-årene, da immunsuppresjonen var basert på azatioprin og prednison, og ga høye utslag på transplantatoverlevelsen. Særlig var det viktig å oppnå god forlikelighet for noen «nye» HLA-vevstyper som ble oppdaget på midten av 1970-tallet, de såkalte HLA-DR-vevstypene. Dette bedret i betydelig grad transplantatoverlevelsen $(1,2)$.

I 1983 ble ciklosporin A ("soppen fra Hardangervidda») introdusert, og senere også en rekke andre langt mer effektive immunsuppressiver. Dette medførte etter hvert liten effekt av god HLA-forlikelighet på transplantatoverlevelsen, da eventuelle avstøtningsreaksjoner vanligvis lot seg reversere med de nye midlene. Transport av nyren medførte også lengre tid uten sirkulasjon (iskemitid), noe som kunne skade nyren. De enkelte sentre ønsket derfor å kunne bruke flere «egne» nyrer selv istedenfor å måtte sende dem fra seg. Dette førte til at man innskrenket sendeplikten til kun å omfatte fullt HLA-forlikelige nyrer, og bare den ene nyren fra hver donor. Utvekslingsprosenten falt til ca. 10-15 \% fra midten av 1980-årene (figur 4).

Som nevnt i ramme 1 kan noen pasienter ha utviklet antistoffer mot HLA-vevstyper, ofte pga. tidligere avstøtt(e) transplantat(er). Disse antistoffene kan være bredt reagerende, dvs. de kan reagere med mange fremmede HLA-vevstyper. Slike pasienter kan det være meget vanskelig å finne en HLA-forlikelig nyre til, og de kan derfor bli stående i årevis på ventelisten. Nå har vi fått metoder til å finne ut hvilke fremmede HLA-vevstyper pasienten ikke har laget antistoffer mot, som kalles akseptabelt HLA-uforlikelige vevstyper. Ved å lete etter givere som bare har pasientens egne HLA-vevstyper, eller bare akseptabelt uforlikelige HLA- 
vevstyper, $\varnothing$ ker pasientens sjanse til å få ny nyre vesentlig. Pasienter med bredt reagerende HLA-antistoffer som har stått på ventelisten i mange år, kan nå få ny nyre fra nylig avdød donor i løpet av få måneder, med et godt resultat. Derfor har man de siste ti år innført primær utvekslingsplikt for akseptabelt uforlikelige nyrer til pasienter med slike HLAantistoffer, noe som har medført en økende utveksling av nyrer (se figur 4).

Dagens utvekslingsregler gir prioritert sendeplikt for fullt HLA-forlikelige eller akseptabelt uforlikelige nyrer til pasienter med bredt reagerende antistoffer, dernest for fullt forlikelige nyrer til pasienter som har mindre bredt reagerende antistoffer, og så for nyrer fra ung giver til barn hvor det er en rimelig grad av HLA-forlikelighet $(4,5)$.

\section{Utveksling av andre organer}

Etter innføringen av ciklosporin A og andre immunsuppressiver ble det også mulig å gjøre andre typer organtransplantasjoner som hjerte-, lunge-, lever- og pancreastransplantasjoner med gode resultater. På grunn av den meget effektive immunsuppresjonen som nå blir brukt, spiller grad av HLA-forlikelighet liten rolle også ved disse transplantasjonene. Men ABO-blodtypeforlikelighet, organstørrelse, og til dels også en viss aldersmatching er viktig ved slike transplantasjoner. De aller fleste transplantasjoner med andre organer enn nyrer skjer med «egne», lokale organer. Men noen pasienter trenger ny lever, nytt hjerte eller nye lunger meget raskt for å overleve. Derfor har man laget kriterier for hastesaker («urgent requests»), hvis et av disse organene må være tilgjengelig innen få dager for å redde pasienten. En slik pasient vil få første tilgjengelige og passende organ i Norden. Figur 5 viser hvor stor andel av transplanterte hjerter, lunger og levere som ble sendt fra ett senter til et annet i perioden 2014-18.

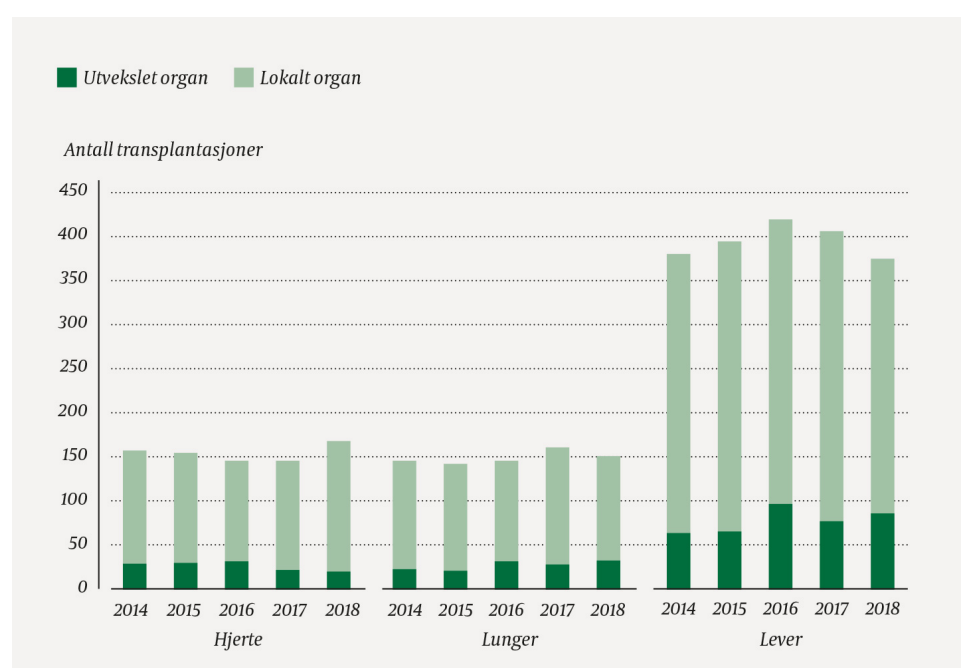

Figur 5 Antall transplantasjoner av hjerte, lunger og lever utført med organ fra eget senter og organ tilsendt fra et annet senter i Scandiatransplant i perioden 2014-18 (tall opplyst fra Scandiatransplant).

\section{Hva har vi oppnådd i de første 50 år?}

Scandiatransplant ble opprettet av klinikere for å gi best mulig tilbud til pasienter som trenger en ny nyre fra en nylig avdød giver. I den første tiden, med mindre effektive immunsuppressiver, oppnådde man en langt bedre overlevelse ved å prioritere optimal HLA-forlikelighet. I de senere år, med mer effektive immunsuppressive medikamenter, har man oppnådd en overlevelse av førstegangstransplantasjon av nyre fra nylig avdød giver til pasienter som ikke har HLA-antistoffer på ca. $95 \%$ etter ett år og ca. 6o \% etter ti år, med liten effekt av HLA-matching (6). Senere har prioritert utveksling ved akseptabel HLAuforlikelighet gjort det mulig å skaffe HLA-forlikelige nyrer langt raskere til pasienter med bredt reagerende HLA-antistoffer som ellers måtte vente lenge på en ny nyre. Til sammen 891 transplantasjoner av nyre fra nylig avdød giver ble utført i medlemslandene i 2018. I 
tillegg kommer 338 nyretransplantasjoner fra levende giver. I 2018 ble det utført 168, 151 og 375 transplantasjoner av hhv. hjerte, lunge og lever i medlemslandene. Mange pasienter som raskt trenger et av disse organene for å overleve, kan nå få dette etter innføring av hasteprogrammet i Scandiatransplant. Det store problemet er fortsatt mangel på organer, som gjør at ventelisten stadig øker. I 1995 var det 1028 pasienter som ventet på en ny nyre i Scandiatransplant, ved utgangen av 2018 var det 1551 . En viktig oppgave er derfor å bedre tilgangen på organer fra nylig avdøde, bl.a. gjennom bedre opplysningsvirksomhet.

Scandiatransplant eies og drives av transplantasjonssentrene. Fagpersoner har utviklet organisasjonen for å sikre et best mulig resultat hos flest mulig pasienter som trenger et nytt organ fra en nylig avdød giver, med utgangspunkt i forskningsbasert kunnskap. Scandiatransplant har medvirket meget sterkt til at nordisk transplantasjonsmedisin er blant de aller beste internasjonalt, både mht. kvalitet og omfang. Dette er den beste garanti for at organisasjonen også vil være svært viktig i fremtiden. Scandiatransplant er en sprek femtiåring og et særdeles vellykket eksempel på hva man kan oppnå med et nært nordisk samarbeid.

\section{LITTERATUR:}

1. Thorsby E. Norsk transplantasjonsmedisin gjennom 50 år. Tidsskr Nor Lægeforen 2006; 126:3305-10. [PubMed]

2. Moen T, Albrechtsen D, Flatmark A et al. Importance of HLA-DR matching in cadaveric renal transplantation: a prospective one-center study of 170 transplants. N Engl J Med 1980; 303: 850-4. [PubMed][CrossRef]

3. Scandiatransplant. Articles of association.

http://www.scandiatransplant.org/about-scandiatransplant/organisation/ArticlesofassociationforFore ningenScandiatransplant10.May2017.pdf(23.1.2018).

4. Scandiatransplant. Powerpoint-presentasjon om Scandiatransplant. http://www.scandiatransplant.org/resources/dias2017.pdf(23.1.2018).

5. Scandiatransplant. Rules for exchange of kidneys from deceased donor within the Scandiatransplant cooperation.

http://www.scandiatransplant.org/organ-allocation/Kidney_exchange_05_dec_2018.pdf(23.1.2019).

6. Scandiatransplant. Powerpoint-presentasjon om nyretransplantasjoner.

http://www.scandiatransplant.org/members/nkg/SCTP_1995_2017.pptx (23.1.2018).

Publisert: 2. mai 2019. Tidsskr Nor Legeforen. DOI: 10.4045/tidsskr.19.0043

(C) Tidsskrift for Den norske legeforening 2020. Lastet ned fra tidsskriftet.no 